\title{
CLIENTS’ SATISFACTION WITH SERVICES FOR PREVENTION OF MOTHER-TO-CHILD TRANSMISSION OF HIV IN DODOMA RURAL DISTRICT
}

\author{
Lyatuu $\mathrm{MB}^{1}$, Msamanga $\mathrm{GI}^{2}$ and Kalinga $\mathrm{AK}^{3}$
}

\begin{abstract}
Objective: The study was conducted to assess clients' satisfaction with PMTCT services on privacy, waiting time and counselling in PMTCT of HIV /AIDS in Dodoma Rural district.

Methods: A cross sectional study was conducted to 208 women assessing Reproductive Child Health (RCH) and PMTCT of HIV services. Data collection method involved both client exit interviews and focus group discussions (FGD) with women attending RCH services. Systematic random sampling technique was used to obtain the required sample of 208 clients for the exit interviews. A total of five FGDs were conducted each with eight to ten people. The data obtained were analysed using Epi Info

Settings: Dodoma Rural district, central Tanzania

Results: Of 113 clients' who accessed PMTCT services, $75.2 \%$ were satisfied with the counselling provided. A significant difference (P = 0.02) was observed between clients with no formal education as compared to those with primary level of education and above. Nearly a quarter of the clients who accessed PMTCT of HIV services were not satisfied with the privacy in the settings providing the service. It was also found that $\mathbf{7 1 . 7 \%}$ of clients accessing PMTCT of HIV service was satisfied with the waiting time spent for the service; however a difference was observed (P $=0.001)$ between clients who accessed services at health centre $(77.6 \%)$ and hospital $(33.3 \%)$.

Conclusion: A quarter of the clients were not satisfied either with the counselling they received on PMTCT of HIV, privacy or waiting time they spent while accessing services. Some of the reasons contributing to dissatisfaction included inadequacy in individual counselling, inadequate on site test supplies and equipment and cost incurred when travelling to seek for PMTCT service from a referral or satellite health facility.
\end{abstract}

\section{Introduction}

\section{General overview of PMTCT and available interventions}

Passing the HIV from an infected mother to her infant is known as mother-to-child transmission (MTCT). It is responsible for most of the acquisitions of paediatric HIV infections. In 2003, an estimated five million people worldwide were newly infected with HIV. Approximately 800,000 of these were children; ninety percent of them being born to HIV infected women and having acquired the virus during pregnancy, labour, or delivery or through breast feeding (1). Each day in the world, 2200 children become infected with HIV, ninety percent of them in sub-Saharan Africa, where MTCT of $\mathrm{HIV}$ is an increasing public health problem (2). Without preventive measures up to $40 \%$ of children born to HIV seropositive women will be infected in this way (3). In absence of any intervention the risk of MTCT of HIV is $15-30 \%$ in non breastfeeding population; breastfeeding by an infected mother increases that risk by $5-20 \%$ (4). In developing countries, where most women breastfeed about one third of the transmission is thought to be through breast milk transmission (5)

\section{PMTCT program in Tanzania}

PMTCT implementation in Tanzania was initiated in 2000 starting with few pilot sites and the scaling up of the program undertaken from 2003. The program has achieved a high acceptance rate of about $93 \%$ in pregnant

Correspondence to: M.B. Lyatuu' Fax Number 022 2150381, Mobile 0784 651614, E-mail; mbenjamin@muchs-harvad.org,

${ }^{1}$ Muhimbili University of Health and Allied Sciences, Dar- es Salaam city and Harvard School of Public Health; HIV/AIDS care and treatment program P.O Box 79810 Dar-es Salaam - Tanzania.

${ }^{2}$ Muhimbili University of Health and Allied Sciences, Community Health Department. P.O Box 65001, Dar-es Salaam - Tanzania.

${ }^{3}$ National Institute for Medical Research, Tukuyu Research station, P.O.Box 538, Tukuyu- Tanzania, margaretbenjamin822@hotmail.com women. A study conducted in Tanzania has shown that the prevalence of HIV is estimated to be $7 \%$ among persons aged 15 - 49 years (6). Among pregnant women attending Reproductive and Child Health (RCH) services the prevalence of HIV is estimated to be $9.6 \%$; however Dodoma region has the highest prevalence (15.2\%) compared to the other regions (7).

The main challenges identified by the Tanzania country PMTCT progress report includes low uptake of Niverapine tablets, low coverage, poor male involvement, children follow-up and low community participation. Another challenge is prevention of HIV transmission through breast-paths given the fact that $9.6 \%$ of HIV infected women opt for replacement feeding (7).

\section{Client satisfaction and associated factors}

Client satisfaction in relation to medical care is predictive of clients' decisions regarding choice of health care plans, compliance with regimens and outcome of the management. The leading model for thinking about satisfaction and perceptions of service quality focuses on whether the customer's expectations are "confirmed" or "disconfirmed" by their perceptions of the service they have received (8). If user's expectations are exceeded by their perceptions of the service they have received then the user is satisfied or even delighted. If their perceptions of the service fall short of their expectations then the result is dissatisfaction.

Some characteristics are associated with general patient satisfaction; these include demographic factors, social economic status and general health status. In addition to these, satisfaction is also influenced by the characteristics of the health provider such as experience, age and gender. Other determinants include the reliability of services, or the assurance that services are provided in a consistent and dependable manner; responsiveness of services or the willingness of providers to meet clients needs; courtesy of providers and security of services, including the security of records (8-9) and 
lastly the physical facilities and equipment available, the appearance of the staff, how easy it is to understand communication materials. However, the most important determinants, as indicated by the regression, appear to be physical comfort, emotional support, and respect for patient preferences (9). A study conducted in rural Bangladesh has revealed that a significant proportion of users $(34.2 \%)$ were not satisfied with the length of time that the facilities were open to the pubic, $(28.2 \%)$ not satisfied with the time they wait to receive the service and $19.5 \%$ of users, who were almost all women felt privacy to be necessary, however privacy was maintained for less than half (45.1\%) of these clients (10).

In relation to PMTCT interventions, health provider play a major role to avail correct information for mothers can reach an informed decision in opting for best alternatives. However it is not known to what extent the clients are satisfied with the context, process and perhaps the cost of the PMTCT service. The context, with respect to PMTCT service, imply the total service package from a whole range of pre-test and post-test counselling, HIV testing, infant feeding options and ARV provision; the process involves the approach used in delivering the service. Thus, it was important to carry out this study so as to portray the quality of the service as perceived by the clients (11). Getting client perspective would also help to know whether the program is being delivered in accordance with their needs and areas that may need improvement.

The aim of this study was to assess clients' satisfaction with the services for prevention of motherto-child transmission of HIV in Dodoma Rural district. The study will provide a report on the average waiting time and client satisfaction with privacy, waiting time and counselling in PMTCT.

\section{Methods and materials}

\section{Study design}

The study employed cross sectional design

\section{Study area}

Dodoma rural district is among the five districts of Dodoma region. The district has 8 divisions, 48 wards and 128 villages. The total number of health facilities is 85 including 78 dispensaries, 6 health centres and one hospital. Four dispensaries and the hospital are owned by faith based organisations while the rest of the facilities belong to the Government. According to June 2007 district statistics; the estimated total population of the district was 492,705 people of which 98,541 are women of child bearing age.At the time of the study a total number of six health facilities were providing PMTCT of HIV services in the area.

\section{Study population}

The study population comprised of women attending PMTCT and other RCH services in the six facilities providing PMTCT services.

\section{Sampling technique}

\section{Exit interviews}

A total of 208 women seeking PMTCT of HIV service in these facilities were approached and invited to participate in the exit interview. This was conducted after the client has gone through the service. Three health providers at district level were selected and trained on procedures for recruiting and administering the questionnaire. Prior to commencement of the study, pre testing of the instruments was done to 15 PMTCT clients attending $\mathrm{RCH}$ care at Muhimbili National Hospital, however not included in the study. The study employed a systematic random sampling to select clients to be included into the study. The total expected attendance for a particular day was obtained using the clinic registers. A sampling interval was calculated by; $X=N / n$ where $(N$ $=$ the total population expected to attend on the specific date, $\mathrm{n}=$ the facility sample size which was $32, \mathrm{X}=$ sampling interval).The first respondent was selected randomly using ballot system from list of numbers between one and thirty two. The rest of the respondents were selected after every $\mathrm{X}^{\text {th }}$ client.

\section{Focus Group Discussions}

A total of five focus group discussions of eight to ten participants, were carried out in five different villages recipient of the PMTCT of HIV program. These were selected through use of simple random technique, from the list of villages served by the facility providing PMTCT of HIV program. On reaching the village level a convenient sampling technique was employed to recruit participants for the FGDs these being pregnant women and mothers with infants. A skilled health provider served as moderator while the main author served as an assistant moderator. The moderator was responsible for conducting discussion according to the guide and keeping conversation flowing. The discussions were conducted in Kiswahili and took between 45 minutes to one hour were recorded using tapes. In this study, information obtained from the FGDs has been used to complement the quantitative method. The FGDs guide covered a range of topics and was flexible to include questions emerging in the relevant themes, among the themes in the guide included privacy and counselling in PMTCT, clients' views on providers' attitudes and adequacy of information provided.

\section{Definition of terms}

In this study:

Client satisfaction was defined as the client's perception that the PMTCT service and provider's performance met her expectations. Client satisfaction was assessed in relation time spent for service, privacy when getting the service and, satisfaction with counselling in PMTCT of HIV.

Waiting time was considered as the time taken from when the client arrived at the hospital or heath centre; 
obtain the services until she walks out of the facility exit gate.

Service time was considered as the time taken from when the provider delivered the specific service sought by client to the time they parted.

\section{Ethical Considerations}

Ethical clearance was sought from the College Research and Publications Committee of Muhimbili University of Health and Allied Sciences (MUHAS). Permission to conduct the research was obtained from the district administrative \& health authorities and incharges of health facilities while consent was sought from individual interviewees. Confidentiality was observed and unauthorized persons had no access to the data collected

\section{Data processing and analysis}

Data cleaning for interviews and a write up of the FGDs was done after data collection. The tapes were transcribed and then summarized according to themes. Coding for the quantitative data was done followed by double data entry and validation to ensure a high quality of data entry. The average waiting time was calculated and a comparison by type of facility was done. Seven scores were derived from seven questions used to assess women's satisfaction with counselling in PMTCT of HIV. Basing on the questions additional variables were created where one was used to denote clients reported to be satisfied in any of the questions assessing satisfaction with counselling and zero to denote dissatisfaction; leading to a scale ranging from $0-7$. This led to categorization of satisfaction with counselling into two; the scores at $25^{\text {th }}$ percentile and below were categorized as not satisfied and the rest satisfied.

Bivariate analysis was also done to examine the association between the clients' satisfaction by the type of facility, type of service, education level and age, also to examine clients satisfaction with the waiting time and privacy when getting services and counselling on PMTCT of HIV.

\section{Results}

\section{Socio-demographic and facility characteristics}

A total of 208 clients attending PMTCT services in six health facilities in Dodoma rural district were interviewed; including $29(13.9 \%), 33$ (15.9\%), 38 (18.3\%), 35 (16.8\%), 16 (16.8\%), 38 (18.3\%) clients from Bahi, Chamwino, Chipanga, Handali, Mundemu health centres and Mvumi hospital, respectively. Health centres comprised $170(81.7 \%)$ of facilities offering PMTCT services. The mean age (SD) of the respondents was 25.9 years $( \pm 5.3)$. The majority $(83.2 \%)$ of the clients were living with partners. Of the total clients interviewed, $65(31.3 \%)$ had no formal education. Youths were $94(45.2 \%)$ and $16(7.7 \%)$ were aged above 35 years. The services sought at the facility by the respondents were categorized into four (Figure 1) using the routine kind of service delivered in $\mathrm{RCH}$ clinics.

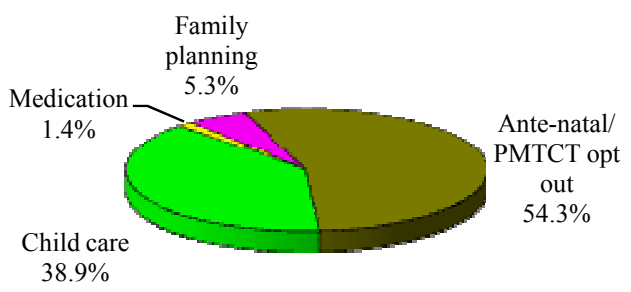

Figure 1: Distribution of type of service sought by respondents attending $\mathrm{RCH}$ clinics Waiting time

The mean (SD) waiting time was found to be 114 minutes $( \pm 66)$. The result showed that a difference exists between the average waiting time and type of facility. The average (SD) waiting time was found to be 108 minutes $( \pm 54)$ at health centre; however it was 144 minutes $( \pm 72)$ at hospital level. The average (SD) time spent by respondents who accessed PMTCT of HIV service was 120 minutes $( \pm 66)$, while for those who accessed other services it was 108 minutes $( \pm 60)$.

A total of $32(28.2 \%)$ of clients accessed PMTCT services were not satisfied with the waiting time spent at the facilities. On the other hand the results showed that there is a statistical difference between type of facility and satisfaction with waiting time. Clients who accessed the service at a health centre were more satisfied with the waiting time than those who accessed the service at hospital level (Table 1).

Table 1: Satisfaction with waiting time by type of service and facility

\begin{tabular}{|c|c|c|c|c|c|}
\hline \multirow{2}{*}{$\begin{array}{l}\text { Characteristic } \\
\text { Type of service }\end{array}$} & \multicolumn{2}{|l|}{ Satisfied } & \multicolumn{3}{|c|}{ Not satisfied } \\
\hline & Number & $\%$ & $\begin{array}{l}\text { Num } \\
\text { ber }\end{array}$ & $\%$ & Total \\
\hline PMTCT & 81 & 71.7 & 32 & 28.2 & 113 \\
\hline Other & 72 & 75.8 & 23 & 24.2 & 95 \\
\hline \multicolumn{6}{|l|}{ Type of facility } \\
\hline Health centre & 130 & 76.5 & 40 & 23.5 & 170 \\
\hline Hospital & $\begin{array}{l}23 \\
X^{2}=4.05\end{array}$ & $\begin{array}{r}60.5 \\
=0.04\end{array}$ & 15 & 39.5 & 38 \\
\hline
\end{tabular}

\section{Satisfaction with counselling on PMTCT of HIV}

The result showed that out of 113 respondents who accessed PMTCT of HIV service 28 (24.8\%) were dissatisfied with the counselling they received on PMTCT of HIV. There was a statistical significant difference in satisfaction between respondents with no formal education and those with primary and above 
education level $\left(\chi^{2}=5.23, \mathrm{df}=1, \mathrm{p}\right.$-value 0.02$)$. While 28 $(90.3 \%)$ of respondents with no formal education were satisfied with counselling in PMTCT, 57 (69.5\%) of those with formal education were not satisfied.

On the other hand through FGDs, results obtained have shown that respondents were concerned with increased cost while seeking for counselling service from facilities that are found outside their locality. As explained by a participant in one of the FGD; 'Tuletewe wataalamu karibu. Kufuata hiyo huduma mjini ni mbali na hatuna hela, kwenda kwenye hivi vituo vingine inatupa usumbufu mara nyingine huduma haipo. Kwa mfano mtu anakutwa ameathirika unadhani atapata nauli ya kufuatilia huo ushauri? Kwa hiyo wataalamu wawepo hapa ili tukishapima waendelee kutuambia nini cha kufanya' literal translation; 'we should be given health providers closer. Fetching for service from town is so far and we do not have money, going to the other health centres creates disturbances sometimes the service is not available. Suppose one test positive, do you think she will have fare to go for follow up counselling every now and then? Therefore, the provider should be based here so that after testing they will keep on advising on what else we should do.'

Also in relation to cost another concern expressed during FGDs was need to ensure the availability of screening tests within proximity as narrated by a participant; 'huduma ya vipimo iwepo hapa sababu ukiambiwa nenda mjini hiyo gharama ya kwenda mjini mwingine anakua hana uwezo wa kufika kule mbali. Kama iko hapa karibu tutakuwa wengi kuja kupima, lakini wakisema mjini ni wengi wanashindwa kwenda, gharama ile anakua hana uwezo. Lakini kama hapa wakituletea kijijini, inaweza ikatusaidia.' Literal translation; 'The testing service should be made available here because if you are told to seek the service from town, others can not afford the cost of going there, it is far. If brought closer, we will be many going for the tests but if they say we seek the service from town, many will not be able to go for the service, it is far and they can not afford. But if made available to this village, it may be of help to us.'

Apart from associated costs inadequate counselling was as well cited during FGDs, as narrated by a participant; 'Ushauri hatupati tukifika kiliniki tunatangaziwa tupime ukimwi na kuambiwa wiki ijayo mje mchukue majibu.' Literal translation; 'We are not counseled; when you arrive at the clinic you are told to test for HIV through announcement. And we are told to come for the result the following week.'

\section{Satisfaction with privacy in PMTCT of HIV services}

Among 208 participants, 76\% of clients were satisfied with privacy when accessing services. Of the three participants captured seeking medication,none of them was satisfied with privacy while $4(36.4 \%)$ and 70 $(86.4 \%)$ of participants who sought family planning and under-five care respectively were satisfied with privacy.

Inadequate confidentiality was also drawn from the experiences in FGDs. In discussions on result sharing and confidentiality, a participant in FGD gave her experience as follows; 'Watajua sababu... , si watatoa majibu ya watu wote. Watakaosikia ndio hao watatoka nayo pale ndio watokaoenda kusems ooh....., au ukiambiwa uje kwenye ushauri nasaha, jinsi ya kuishi kwa matumaini, sijui ule mbogamboga utagundulika tu.' Literal translation; 'they will know because...., and they will give results to everyone. Those who hear that are the ones to spread to others $\mathbf{O R}$ if you are told to attend counselling, and if advised to eat vegetables, for sure they will discover.' A similar scenario was also given by another participant who narrated her experience as follows; 'Mimi kwa mimba ya huyu hapa (mama anaonyesha mtoto) tulipima tukiwa watu 21 ilikuwa siku ya Jumatatu tukaambiwa twende siku ya Ijumaa tukajue majibu. Wote tukakusanyika, wakaanza kutuambia, jamani nashukuru toka nimeanza kupima sijapata kuona watu kama nyie, yaani wote mpo wazima. Hakuna cha gono, wala kaswende wala ukimwi. Kwa hio endeleeni hivyo muwaambie na waume zenu muendelee hivyo hivyo.' Literal translation; 'This is my experience with the pregnancy of this child (mother showing her child); we were 21 when we went for testing, it was Monday and we were told to return back for our results on Friday. While gathered, she started telling us that I (provider) appreciate since I embarked on testing I have never come across such a group, you are all healthy. You have neither STIs nor HIV. So you should tell your husbands as well you should maintain this.'

\section{Discussion}

According to some reports, delivery of health services is expected to respond to preference and client demand (9); thus client satisfaction is a useful measure in assessment of quality of the service. This study has focused on views of users of RCH services and has identified areas in the PMTCT service that need to be addressed for better management.

However the weakness for this study was the representativeness of participants for the FGDs. Ensuring voices of the marginalized group in the population was a challenge since selection of the participants was done with help of community leaders; thus there may be a tendency for them to select the most vocal and active members or volunteers to participate. This was addressed by clearly explaining the purpose of the study to the leaders and also explaining the need to identify the less active members as well.

The overall average waiting time was found to be 114 minutes. This was not consistent with a study which has shown a mean waiting of 240 minutes equivalent to four hours (12). The average waiting time spent was higher in the hospital than in the health centre setting which was 144 and 108 minutes respectively; however larger proportion of participants attending services at health centre were more satisfied. These differences can be explained by the fact that less skilled providers are working in the lower level hard to reach areas which may result into inability to adhere with the standard guidelines in the provision of service. Therefore little time being spent in service has implication on the average waiting time and also the quality of service the clients received, given the fact that rural settings in Tanzania are currently facing health staff shortages. 
A significant proportion of clients were not satisfied with the waiting time for the service. This may have happened due to two reasons; one, the actual time spent for the service being little in comparison to the total waiting for the service. In this case the client may relate the kind of service she has received to the time differences; ending up questioning ' is this all you can say/tell or give for all the time I have been waiting?' This could be the case especially for heath centers where the average waiting time was generally lower. The other reason could be that actual time spent for the service was too long that some clients could not bear with it this being the case for the hospital level. The above results are consistence with a study conducted in rural Bangladesh which reported that $28.2 \%$ of clients were not satisfied with the waiting time (10).

Also as revealed during FGDs, client confirmed that they still had challenges to pursue some of the health interventions resulting from the counselling sessions. In one of FGD session during discussion on the adequacy of information they receive, a participant reported 'because of our low understanding we end up saying how do they see me?' For a client to remain with such a query is an indication of withheld unlearned doubt. As confirmed by participants in the FGD that counselling was inadequate. This finding is consistent with findings with a study conducted in Kenya which has found inadequacy information given to clients seeking PMTCT service [13].

The information obtained through quantitative method has shown that majority $(76 \%)$ of the clients confirmed to be satisfied with counselling in PMTCT. Also as narrated by participants in the FGDs the counselling provided was inadequate, 'They don't even give counselling like for my case, I was not given any counselling'. This finding is consistence to a study conducted in Kenya, where client attending Prevention Clinic for the first time confirmed no counselling was given to her (13). This finding is not consistent with a study conducted in South Africa, which has shown client satisfaction with counselling of $100 \%$ for those seen by nurses and satisfaction been $80 \%$ for those seen by community volunteers (14).

In this study it has been shown that clients with no formal education were more satisfied with counselling than those with primary level education and above. The result is consistence with previous findings suggesting that educated women may be more aware of treatment options available or lack of options and therefore they will be less inclined to participate (15). On the contrary women with more years of education may falsely view themselves as more knowledgeable and therefore decline participation to counselling sessions.

It was also found that in areas where this service was to be obtained from a satellite/central facility identified to provide the service; clients were concerned with increased cost (much more transport) to seek counselling service outside their locality. This is similar to findings that had depicted that minimum staffing should be available for implementation and successful integration of PMTCT services since VCT is an important entry point for care and referral to the community network as well as medical HIV care services $(1,16)$.
The proportion of client satisfied with privacy was $74.3 \%$ among clients who accessed PMTCT of HIV service. This finding differs from a study conducted in Kenya which found that $97 \%$ found the privacy in counselling of PMTCT to be good (13). Several reasons were given that bring about satisfaction; however some unique responses like "to some extent" indicated the need for additional use of ranking scale to assess the level of satisfaction.

Satisfaction with privacy when getting service was higher in hospital than in health centres settings. This may be a result of the length the facility had been providing PMTCT services. A study conducted in Dares-Salaam has shown that sites that have been in operation for longer would be more likely to have a more refined system of performing the required procedures (16). On the other hand it may be a result of unavailability of adequate structures, supplies and skilled personnel to support providers to perform the required procedures.

However, generally privacy and confidentiality was inadequate which has been explained by experiences from FGDs. This is consistence with a study which has similar result through a non participant observation (13). Inadequate privacy violates clients' rights to confidentiality in that their information should remain between the counsellor and counselee only. Some clients have reported this to be one of the setbacks to the services. Similar information was found in a study conducted in South Africa (14). It also came out clearly that in this community they have a misconception that counselling is for people who are already infected and thus attending counselling is an indication of being infected. This may have resulted from their experience with getting the service without any counselling and thus for a person to be counseled mean she must have a problem.

Further it was noted through FGDs that apart from the fact that counselling was inadequate, confidentiality was not given enough consideration when sharing results. It becomes even worse when clients' names are mistaken and consequently ending up providing results to unintended client. This was the experience from the health centres which are not equipped with on site testing supplies/equipments. Such experience is psychologically and emotionally traumatizing.

\section{Conclusion}

A quarter of clients were not satisfied with either counselling in PMTCT of HIV, privacy or waiting time when accessing the service. Some reasons which bring about this can be concluded to arise from inadequate individual counselling, inadequate privacy when reporting test results, as well as unintentional mixing up of test results which resulted from inadequate on site testing supplies/equipments. The average waiting time was higher in hospital than in health centre settings. Generally more than $50 \%$ of clients spend less than 20 minutes in receiving a service although the average waiting time was relatively longer. 


\section{Recommendations}

- Heath providers with counselling skills are required in large numbers to cope with the scaling up of PMTCT program in the area. Whenever possible this should be coupled with training community volunteers to compliment the health care efforts. This move would reduce the waiting time.

- There is a need to assess the quality of counselling services provided as indicated in the national PMTCT guideline. This would improve services and hence client satisfaction.

\section{Acknowledgement}

We gratefully acknowledge Dr Sylvia Kaaya, Dr Candida Moshiro, and Mr Faustin Mayunga in the whole process of data analysis. We thank Dr E.J. Mwenemile, District Medical Officer, Dodoma Rural and his team for providing us with the necessary information and support in the whole period of data collection. The same should be extended to Mr Ramadhani Nyenze and Immanuel Mwalyambwile who devoted their time to assist with the field work.

\section{References}

1. Perez F, Gliemann J, Mukotekwa T, Miller A, Glenshaw M, Mahomva A, Dabis F. Prevention of mother-to-child transmission of HIV: evaluation program in a district hospital in rural Zimbabwe. British Medical Journal 2004; 329:1147-1150 doi10.1136/bmj.329.7475.1147

2. Becquet R, Ekouevi DK, Viho I, Sakarovitch CMS, Toure H, Castetbon K, Coulibaly N, Marguerite TK, Laurance B, Francois D, Valeriane L. Acceptability of Exclusive Breast-Feeding With Early Cessation to Prevent Abidjan, Côte d'Ivoire. Journal of Acquire 2005; 40(5): 600-608

3. NACP. The national guidelines for prevention of mother-to-child transmission of HIV Volume 2, Ministry of Health Tanzania 2004, www.nacp.org.publications accessed 19 March 2007.
4. World Health Organization. Antiretroviral drugs for treating pregnant women and preventing HIV infection in infants. Guidelines on care, treatment and support for women living with HIV/AID and their children in resource - constrained settings 2004; pg 4, ISBN $92 \quad 4 \quad 1592095$, resource - constrained settings 2004; p
www.who.int/hiv/en accesses 23 October 2007 .

5. Guay LA, Musoke P, Fleming T, et al. Intrapartum and neonatal single-dose nevirapine compared with zidovudine for prevention of mother-to-child transmission of HIV-1 in Kampala, Uganda: HIVNET 012 randomized trial. Lancet 1999; 354(9181): 795 - 802.

6. Tanzania Commission for AIDS, National Bureau of Statistics, ORC macro Calverton. 2005; Tanzania HIV/AIDS indicator survey 2003-04.

7. NACP. PMTCT Annual Report 2000-2005; Tanzania Ministry of Health and Social Welfare 2006. www.nacptz.org.publications accessed 18 May and 2007.

8. Nick D, Joanna B, Lisa B. Satisfaction with Public Services, A Discussion Paper. November 2001

9. Jenkinson C, Coulter A, Bruster S, Richards N, Chandola T. Patients' experiences and satisfaction with health care: results of a questionnaire

10. Aldana JM, Piechulek $\mathrm{H}$, Al-Sabir A. Client satisfaction and quality of health care in rural Bangladesh. Bulletin of the World Health Organization 2001; 79(6):512-517.

11. Steinbock CM, Agins BD, Bothman JR, Eckholdt HM, Chin JJ. Bilingua HIV- specific Patient Satisfaction Survey (PSS- HIV) for HIV Ambulatory Care settings, Abstract No. MoPeD3762. International Conference on AIDS 2004; 15: 11-16.

12. Ekanem EE, Gbadegesin A .Voluntary Counselling and Testing (VCT) for Human Immunodeficiency Virus: A Study on Acceptability by Nigerian Women Attending Antenatal Clinics. African Journal of Reproductive Health Women Attending Anter (Aug);8(2): 91-100.

13. Moth IA, Ayayo ABCO, Kaseje DO. Assessment of Utilization of PMTCT Services at Nyanza Provincial Hospital, Kenya. Journal of Social Aspects of HIVAIDS 2005; 2(2): 244-250.

14. Ginwalla SK, Grant AD, Day JH et al. Use of UNAIDS tools to evaluate HIV voluntary counselling and testing services for mineworkers in South Africa. AIDS Care 2002; 15(5):707-726

15. Westheimer EF, Urassa W, Msamanga G et al. Acceptance of HIV Testing among pregnant women in Dar-es-Salaam, Tanzania. Journal of Acquired Immune Deficiency Syndromes 2004; 37(1): 1197-1205

16. Antelman G, Fawzi MCS, Kaaya S et al. Predictors of HIV-1 serostatus disclosure: a prospective study among HIV-infected pregnant women in Dar-es-Salaam, Tanzania. AIDS 2001; 15(14): 1865-1874. 